\title{
An Investigation of Avoidance Behaviour in Writing
}

\author{
Noor Hanim Rahmat ${ }^{1, *} \&$ Haeza Haron ${ }^{2}$ \\ ${ }^{1}$ Akademi Pengajian Bahasa (English Department), Universiti Teknologi MARA, Malaysia \\ ${ }^{2}$ School of Languages, Literacies and Translation, University Science Malaysia \\ *Corresponding author: Akademi Pengajian Bahasa (English Department), Universiti \\ Teknologi MARA, Malaysia. E-mail: patanim@gmail.com
}

Received: October 5, 2020 Accepted: March 16, 2021 Published: March 25, 2021

doi:10.5296/ije.v13i1.17779 URL: https://doi.org/10.5296/ije.v13i1.17779

\begin{abstract}
Writing skills are needed across all courses, across all discipline research papers, projects, reports, assignments. However, many claimed they have "writers' block" which hinders them from writing as often as they hoped, or as much as they wished. Although many may think writing block stems from a writer who only lacks content. However, more often than not, writing block is caused of writers' fear of writing. The writer becomes so overwhelmed by the fear of writing that he/she is paralyzed with fear. Fear in writing is a learned behaviour that will influence the writer's behaviour towards writing-related environment. Past studies have shown that one way for people to not live in fear is to avoid the action totally. This study is done to investigate the facets of avoidance behaviour to avoid writing-related activities. 108 participants responded to a survey. The instrument used is a survey with 6 sections. The first section is demographic profile. The second section is on cognitive avoidance and it has 4 items. The third section is somatic avoidance with 7 items. The fourth section is protective avoidance and has (i) problems with punctuation (9 items), (ii) problems with language use ( 7 items), and (iii) problems with writing skills ( 9 items). The fifth section is situation with 5 items and the last section is substitution with 7 items Findings reveal that when writer fear writing, they may resort to avoidance behaviour such as cognitive, somatic, protective, situational and also substitution avoidance.
\end{abstract}

Keywords: writing skills, cognitive avoidance, somatic avoidance, protective avoidance, situational avoidance and also 


\section{Introduction}

Learners leaving schools might take some time to get used to learning different writing skills. The types of writing in secondary school focus on narrative and reflective formats. Brown (2001) labels this type of writing as real writing. Real writing is writing where the reader expresses his /her thoughts/emotions into the writing. The audience may or may not know what the writer plans/needs to have in the text.

On the other hand, the types of writing in higher institution of learning focus more on informative. Brown (2001) describes this type of writing as display writing. Display writing is primarily intended for the teacher who already knows the answer that the student is addressing. Therefore, students studying in higher institutions are expected to focus more on display writing. Different levels of students (undergraduate to postgraduate) may differ in the way they present their display writing.

Writing skill is universal and it functions to facilitate both the social and academic communication. According to Bradford (2019), writing connects the oral thoughts into written form. Writing skills are needed across all courses, across all discipline research papers, projects, reports, assignments (Brown, 2001). However, many claimed they have "writers" block" which hinders them from writing as often as they hoped, or as much as they wished. Some researchers reported that people who 'writers' block" actually fear writing. According to Fareed, Ashraf and Bilal (2016), writing fear is a hindrance that many writers face either at the beginning of the writing process, during the writing process, or anytime throughout the writing experience. Sadly, this simple writing fear may often escalate into writing anxiety and if left unchecked, writing anxiety can lead to negative impact to the writers. Why do writers face writing anxiety?

This study is done to investigate the reasons why academic writers face writing anxiety. Specifically, this study explores the different facets of avoidance behaviour when it comes to writing. This current study is done to answer the following questions;

(a) What are the different facets of cognitive avoidance for academic writers?

(b) What are the different facets of somatic avoidance for academic writers?

(c) What are the different facets of situational avoidance for academic writers?

(d) What are the different facets of protective avoidance for academic writers?

(e) What are the different facets of substitution avoidance for academic writers?

\section{Literature Review}

\subsection{Fear of Writing}

Fear is sometimes seen as a learned behaviour, it can influence others, and it is also an interaction between thoughts and behaviour. According to Santrock (2009), fear can be understood from three different perspectives. The theories that explain the fear learning can be derived from the understanding of three classical behaviour theory. The first is behaviourism. 


\section{Ml Macrothink}

This is a learning theory that explains human behaviours and responses in terms of learned behaviour, operant conditioning. Operant conditioning is behaviour through reinforcement. One example of negative reinforcement is a person keeps doing the same mistake because no one actually corrected/reviewed. Next is social cognitive theory. This theory focuses on an individual's thoughts, beliefs, to determine his/her emotions and behaviours. Next, in the social cognitive theory, there is a variation on cognitive theory that addresses the effects that others have on a person's behaviour. According to the principles of social cognitive theory, people learn not only through their own experiences but also by watching others. Finally, the cognitive-behaviourism is a blended theory that incorporates both cognitive and behavioural elements. According to cognitive-behavioursim, a person's responses are based on a complex interaction between thoughts and behaviours, with thoughts and feelings playing a major role in the person's behaviour.

Fear in writing is a learned behaviour that will influence the writer's behaviour towards writing-related environment. According to Rahmat (2019b), fear in writing begins with the writers' perception of it being difficult (Figure 1). The writer also blames the environment (classroom setting) for their fear.

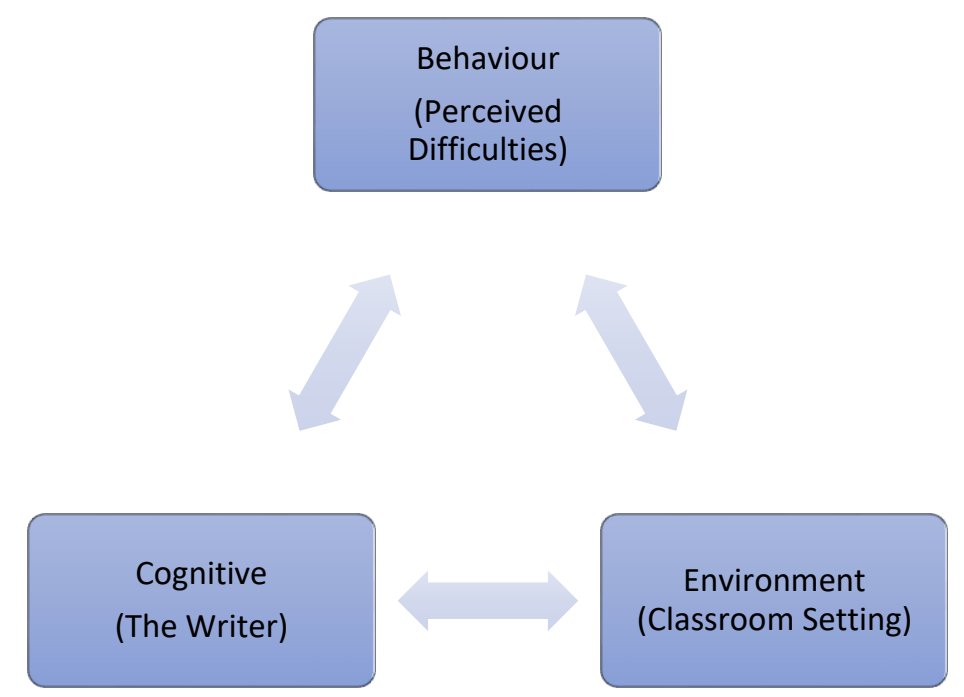

Figure 1. Fear of Writing (Source: Rahmat, 2019b)

\subsection{Fear and Avoidance Behaviour}

The popular quote "fight or flight" is seen as appropriate to describe how some writers who fear writing decide to "take flight"; thus, choosing to avoid writing. Rachman (1977) reports that fear is learned through one or a combination of the following learning pathways. The first is (a) direct conditioning-exposure and this type of fear stems from being constantly exposed to this condition. Next is (b) vicarious learning-learned and this type of fear occurs by observing the fear responses of others. The last type is negative information/instruction. Negative information about a stimulus may also explain the development and exacerbation of feared 
situations and objects that have not been personally experienced Negative information may increase beliefs about the danger posed by a particular stimulus. If a subsequent interaction with the stimulus is encountered, this is likely to produce a fear reaction.

Not all types of fear are the same. According to Cheng (2004), there are several types of fear. The first type is (a) somatic anxiety and this is the physiological effect of the anxiety experience is reflected in increased autonomic arousal and unpleasant feeling states such as nervousness and tension. The second type is (b) cognitive anxiety, which is the mental manifestation of anxiety, or the specific thought processes that occur during anxiety, such as concern or worry. The last type is (c) avoidance behaviours are any actions a person takes to escape from difficult thoughts and feelings. These behaviours can occur in many different ways and may include actions that a person does or does not do.

However, avoidance behaviour stems from several reasons. According to Dore (2018), there are 5 types of avoidance bahaviour; (a) situational avoidance, (b) cognitive avoidance, (c) protective avoidance, (d) somatic avoidance, and, (e) substitution avoidance.

(a) Situational avoidance

This is the most commonly used kind of avoidance. This is when a person avoids the activity (writing-related) based on situations. Situational avoidance reinforces fear. The person uses different situations to avoid doing the activity that he/she does not like.

(b) Cognitive Avoidance

Cognitive avoidance is about avoiding internal events such as unpleasant or distressing thoughts or memories. With this type of avoidance, people usually take actions to suppress or reject the experience of certain kinds of thoughts that feel unpleasant or overwhelming. Strategies to avoid unwanted internal events may involve consciously telling oneself not to think about something, or taking action to "numb out" to the unwelcome thoughts. Cognitive avoidance can also show up as worry and rumination.

(c) Protective Avoidance

People who use protective avoidance display excessive safety behaviours that might include checking, cleaning, over-preparing or perfectionism. The need to be perfect may lead them to not want to proceed with an activity that they know they have weaknesses and difficulties in.

(d) Somatic Avoidance

Anyone who has ever experienced anxiety knows that it is typically a combination of mental and physical symptoms. Tightness in the chest, shallow breathing, increased heart rate,and, sweaty palms may all show up along with distressing thoughts when a person feels anxious. Other emotional challenges - like depression, anger, grief, and heartbreak — also come with noticeable somatic symptoms.

(e) Substitution Avoidance

Substitution avoidance is essentially trying to replace one feeling with another. A person might 
replace grief with anger, or another emotion that feels more tolerable for her at the time. Numbing out is also a form of substitution avoidance. Channeling one's attention to other unrelated activities are examples of successful substitution avoidance behaviour.

\subsection{Difficulties in Academic Writing}

One negative consequence of fear of writing is writers' block. According to Rahmat (2020), writers' blocks are caused by many reasons. When writers write, they face rhetorical problems. Past studies have shown that these problems are easily solved by skilled writers. However, less skilled writers may take a longer time to get out of the rhetorical problems. Rhetorical problems can be categorized into two. Firstly, many writers face problems due to their failure to attend to their own goals (writers' own goal). Next, writers also face problems with the rhetorical situation. Rhetorical situations can be categorized as problems with the assignment and problems with the audience.

One way to understand the writer is by understanding the components of the rhetorical situation. According to Last and Neveu (2019), there are five components of rhetorical situation and they are (a) purpose, (b) audience, (c) message, (d) culture and context, and, (d) writer. Purpose refers to the "why" the writer is writing. There are three purposes for communication, and they are (a) to create a record, (b) to give a request information, and (c) to persuade. A good writer conducts an audience analysis before beginning the writing process. Message refers to what information the writer wants to communicate. Context helps creates the need for the writing. In other words, what has happened or needs to happen that creates the need for communication? The context is influenced by timing, location, current events, and culture, which can be organizational or social. Finally, Writers would take into consideration past experiences, and also the knowledge he /she can bring into the situation.

Fear of writing can be traced from existing problems. Klimova (2014) and Rahmat (2019a). Figure 2 below shows the categories of difficulties writers face. Problems can be divided into 3 categories; (a) Linguistic difficulty (grammar, vocab, language use), (b) Physiology difficulty (no interaction from reader), and (c) Cognitive difficulty (formal instruction -eg spelling, punctuation, capitalization, paragraphing).

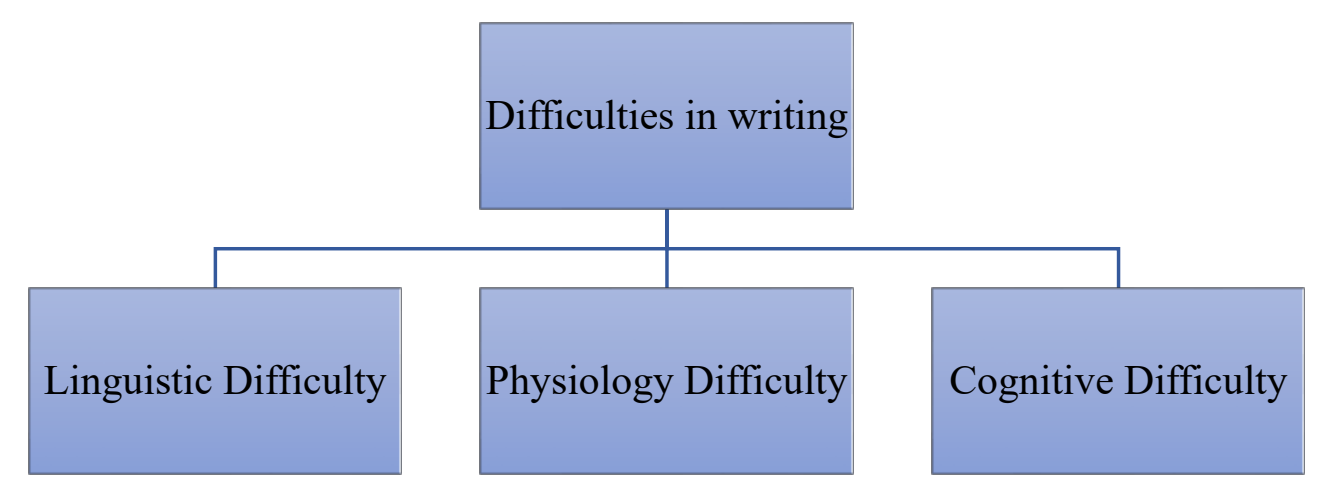

Figure 2. Difficulties in Writing (source: Klimova, 2014 and Rahmat, 2019a) 


\subsection{Past Studies}

\subsubsection{Anxiety in Writing}

When it comes to writing fear, anxiety leads to more problems for the writer; nevertheless, these problems are caused by difficulties faced by the writers. The study by Sabti, Md Rashid, Nimehchisalem, and Darmi (2019) examined individual differences in Iraqi EFL learners' writing anxiety, writing self-efficacy, and writing achievement motivation in the Iraqi EFL context. The findings of this study discovered that the higher the writing anxiety level, the poorer the writing performance, whereas the higher the writing self-efficacy and writing achievement motivation level, the better the writing performance. The findings of this study also indicated that both writing self-efficacy and writing anxiety, and writing anxiety and writing achievement motivation were negatively correlated, whereas writing self-efficacy and writing achievement motivation were significantly and positively correlated. This study suggests that these factors need to be taken into consideration in EFL writing instruction to facilitate the teaching and learning process of EFL writing, which in turn would help enhance the EFL undergraduates' writing ability.

\subsubsection{Problems in Writing}

Writers fear writing and become anxious when it comes to writing-related activities. This writing can be caused by several problems. The study by Mohamed Alfaki (2015) identified university students' writing problems in the English language and suggest ways of solving those problems. The findings reveal that university students have various writing problems: language problems at the levels of morphology and syntax; usage errors, and mechanical mistakes, that is, spelling, punctuation and capitalization, lack of several writing development skills, cognitive problems, and graphomotor problems. In the light of these findings a number of recommendations have been made: Teachers should remind students to revise their written work aloud. When they speak, they will make natural pauses and this will help them in punctuation. Spelling mistakes can be corrected by using dictionaries or spellcheckers. Usage mistakes and grammar mistakes will eventually disappear, if the students read extensively in English. Mohamed Alfaki (2015) reported that among some of the causes of learners' problems in writing are (a) the Nature of writing process-complex process, (b) Learners lack motivation, (c) inadequate time, (d) lack of practice, and also (e) teachers' Feedback

Next, Fareed, Ashraf, and Bilal (2016) investigated problems in Pakistani undergraduate ESL learners' writing and factors that hinder their writing skills. It also aimed at obtaining suggestions on how to improve Pakistani ESL learners' writing skills. For this purpose, focus groups of Pakistani English language teachers and undergraduate ESL learners were conducted. Writing samples were also collected from 30 ESL undergraduate learners to find the major problems in their writing. The interviews and essays were analyzed using thematic content analysis. The findings reveal that the major problems in Pakistani undergraduate ESL learners' writing are insufficient linguistic proficiency (including command over grammar, syntax, and vocabulary), writing anxiety, lack of ideas, reliance on L1, and weak structure organization. These challenges are influenced by various factors including untrained teachers, ineffective teaching methods and examination system, lack of reading and writing practice, large 
classrooms, low motivation, and lack of ideas.

\subsubsection{Difficulties Writers Face}

The study by Fadda (2012) was conducted to determine what difficulties King Saud University students encounter when learning to write academic English and to differentiate between students' learning needs and objectives. Analysis of the data showed that English as a second language (ESL) students face many difficulties and stresses in their academic writing, such as difficulty distinguishing between spoken and written English, making an outline before writing a draft, identifying the skills needed for successful writing, and avoiding plague words and phrases.

Qasem and Zayid (2019) conducted a study on undergraduates' writing difficulties when writing their final year project. The results from the study showed that around $70 \%$ of the participants who are writing research or conducting research projects in English is one of the predominant challenges for them. Around 50\% prefer to conduct their research in L1. The study explored various and common challenges/difficulties during writing the research proposals and projects such as: difficulty in deciding the topic for research, lack of good knowledge of the methodology, the inability of finding modern, specialized and related references, lack of interest in research, lack of understanding of the subject matter, lack of time, and research guiding. A similar study was done by Moses and Mohamad (2019) and found that writers faced challenges such as lack of vocabulary, grammar, and spelling skills. They are sometimes not ready for the writing activities besides not having enough exposure to reading materials.

The study by Ibnian (2017) aimed at exploring difficulties that university students face when they write in English as a Foreign Language (EFL). It also aimed at proposing solutions to help EFL learners overcome writing difficulties. The sample of the study comprised 82 English majors from the World Islamic Sciences and Education University in Jordan. Instruments of the study included a questionnaire on difficulties that may face English majors while they write in English. The questionnaire also included an open-ended question on suggestions and solutions that can help the students overcome writing difficulties. The results revealed that "lack of ideas" topped difficulties faced by Jordanian EFL students in writing class, followed by "the incorrect use of mechanics of writing". The study also revealed that "lack of clear assessment instruments and marking schemes" occupied the third rank, while "time restriction" ranked fourth. "The unsuitable methods of teaching writing" and "vocabulary restriction" occupied the fifth and sixth ranks respectively, while "topic inappropriateness" and "lack of materials for consulting" occupied the seventh and eighth ranks. Finally, "grammar difficulties" and "lack of teacher's help" ranked ninth and tenth respectively.

Finally, Ariyanti and Fitriana (2017) explored the difficulties faced by EFL students in essay writing as well as exploring their learning needs to have a better quality of English composition. Examining essays and administering open-ended questionnaires were done to 33 students of the English Department at Widya Gama Mahakam University, Indonesia, to find studentse difficulties in broad-spectrum. In addition, a semi-structured interview was conducted on the writing lecturer was also conducted to dig his perception related to challenging matters about teaching essay writing. The findings showed that students have major difficulties in 
grammatical, cohesion and coherence terms. The lecturer admitted that limited time and a big number of students in one class became his great barriers to improve the quality of the students ${ }^{\text {ce }}$ essay. These facts drive new challenges for the writing lecturer in two ways; 1) the lecturer should guide students properly by using step-by-step procedures so that the students feel comfortable in writing the essay, and 2) explicit explanation related to the revision given is needed. It is important to note that this issue demands a new and effective teaching essay writing strategy to achieve fruitful outcomes of the teaching and learning process especially in an essay writing context.

\subsection{Theoretical Framework}

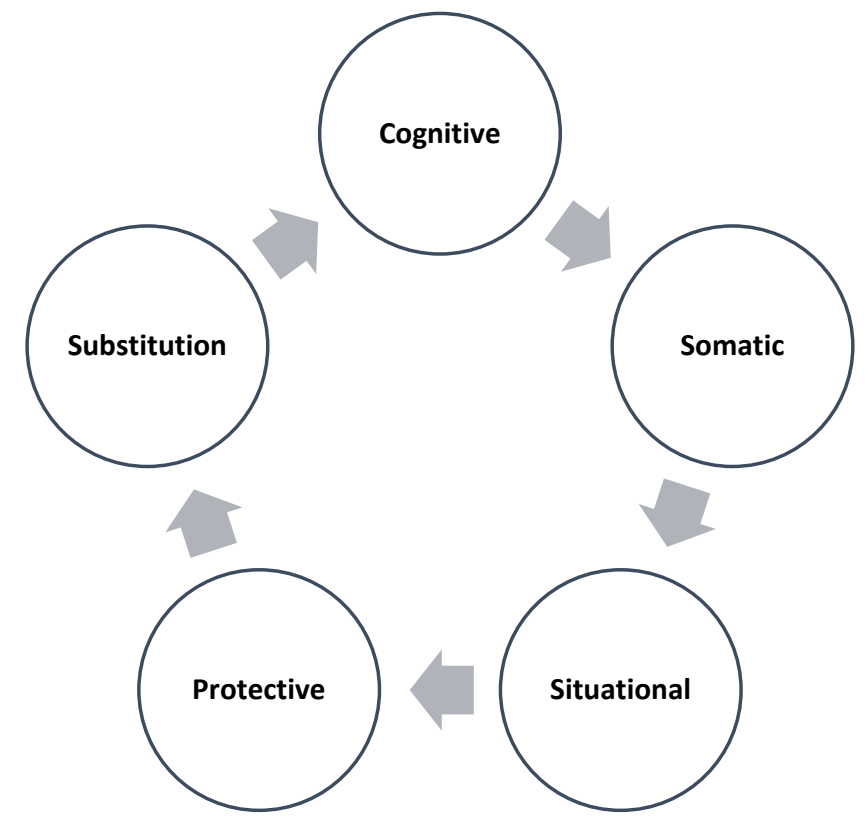

Figure 3. The Cycle of Avoidance in Writing (Source: Dore, 2018)

The theoretical framework of this study is rooted by the 5 main categories of avoidance behaviour by Dore (2018) and writing difficulties by Mohamed Alfaki (2015) and Rahmat (2019). The list of writing difficulties was combined to fit into the different categories of avoidance behaviour (figure 2).

\subsubsection{Cognitive avoidance}

When it comes to writing, cognitive avoidance refers to the writers' thoughts while they write. They may feel nervous. They may feel worried and uneasy if they know their essay will be evaluated.

\subsubsection{Somatic Avoidance}

For some writers, this fear they have in their minds may escalate into their actions. They may sometimes be stressed under time constraint. Their mind may go blank when they start to work on an essay. They may also tremble or perspire when they have to write under time pressure. They may have their thoughts jumbled when they write. In adverse cases some writers may 
feel their body rigid and tensed when they write.

\subsubsection{Protective Avoidance}

Writers may take the protective avoidance mode by finding excused for themselves. They may argue that they have problems in;

\section{(a) Punctuation}

Some writers claim they will not write because they have problems with their punctuations. They may claim they face problems with punctuations, question marks, commas, or other punctuation skills that hinder them from writing.

(b) Language Use

Some writers claim they could not write as they have problems with their language use. They may feel inferior to their fellow writers and thus avoid writing.

(c) Writing Skills

Some writers use their lack of writing skills as an excuse. Skills like summarising, paraphrasing, citation, and other writing-related skills may hinder them from wanting to write.

\subsubsection{Situational Avoidance}

For this current study, situational avoidance refers to the environment where the writers are in. The writers may see their environment as a hindrance from writing from their personal perspectives or even from their perspectives of their writing teacher.

\subsubsection{Substitution Avoidance}

The culmination of the writing fear may then push the writers to turn to other activities apart from writing. They may either directly avoid writing or use other excuses so their writing activity is either delayed or aborted.

\section{Methodology}

108 respondents participated in this quantitative study. The instrument used is a survey with 6 sections. The first section is demographic profile. The second section is on cognitive avoidance and it has 4 items. The third section is somatic avoidance with 7 items. The fourth section is protective avoidance and has (i) problems with punctuation (9 items), (ii) problems with language use (7 items), and (iii) problems with writing skills (9 items). The fifth section is the situation with 5 items and the last section is substitution with 7 items. A reliability analysis was done on the instrument (table 1) and Cronbach alpha was reported to be 0.961 .

Table 1. Reliability Statistics for Instrument

\begin{tabular}{ccc}
\hline \multicolumn{2}{c}{ Reliability Statistics } \\
\hline Cronbach's Alpha & N of Items \\
.961 & 56 \\
\hline
\end{tabular}




\section{Macrothink}

Data was analyzed using SPSS to reveal frequency in terms of mean scores. Findings are presented in the form of bar charts.

\section{Findings}

\subsection{Introduction}

With reference to this current study's theoretical framework, writers' fear begins with their cognitive avoidance. This is followed by their somatic avoidance and this leads the writers to be protective. The writers blamed their situation for this fear and may end up substituting writing-related activities to non-writing relate done. This section thus presents the findings by answering the research question. The 5 research questions are;

(f) What are the different facets of cognitive avoidance across different levels of academic writers?

(g) What are the different facets of somatic avoidance across different levels of academic writers?

(h) What are the different facets of situational avoidance across different levels of academic writers?

(i) What are the different facets of protective avoidance across different levels of academic writers?

(j) What are the different facets of substitution avoidance across different levels of academic writers?

\subsection{Cognitive Avoidance}

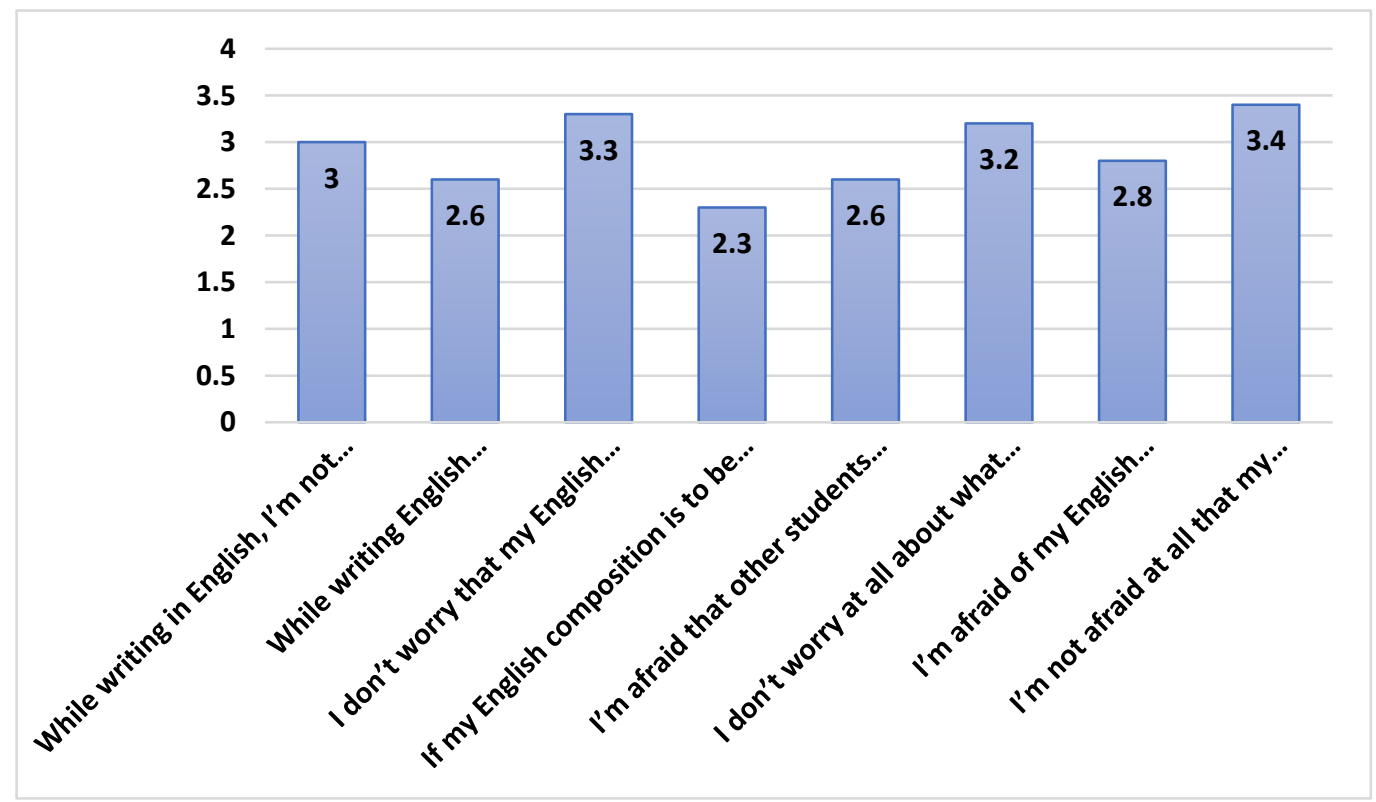

Figure 4. Mean Score for Cognitive Avoidance 
(k) This section presents the answer to research question 1: What are the different facets of cognitive avoidance across different levels of academic writers?

Figure 4 presents findings for cognitive avoidance in terms of mean scores. The highest mean is for the leaners felt they were "not afraid if their essays were rated very poor" (3.4). They also did not "worry about what other people would think of their English compositions" (3.2).

\subsection{Somatic Avoidance}

This section presents data to answer research question 2: What are the different facets of somatic avoidance across different levels of academic writers? Somatic avoidance refers to combination of mental and physical reactions that a person displays to avoid starting/continuing writing-related activities.

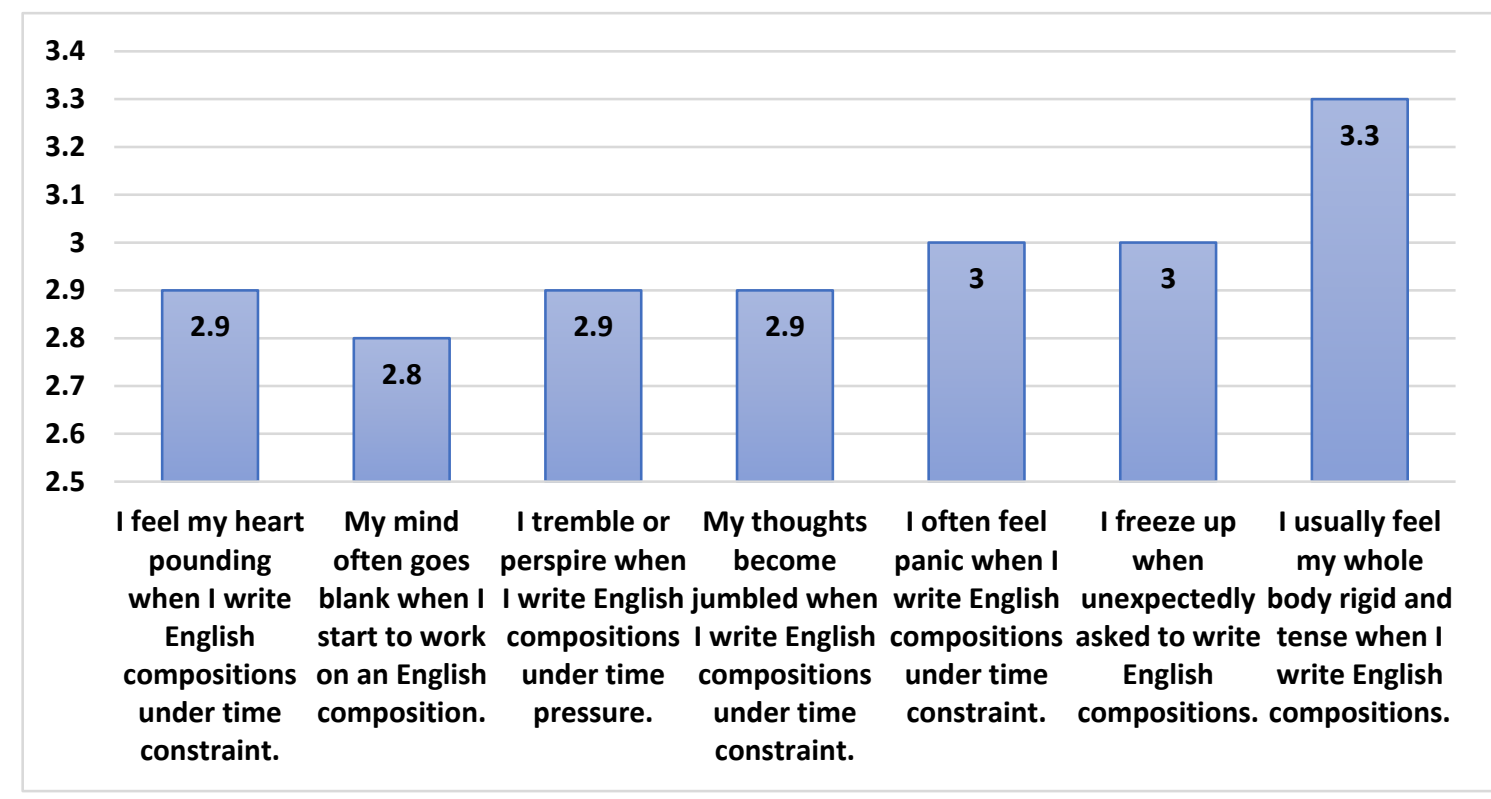

Figure 5. Somatic Avoidance

Figure 5 presents mean score for somatic avoidance. The highest mean is when the writers "felt their whole body rigid and tensed when they write in English compositions" (3.3). The lowest mean score is when the writers "often go blank" (2.8).

\subsubsection{Situational Avoidance}

This section presents findings to answer research question 3: What are the different facets of situational avoidance across different levels of academic writers? What are the different facets of situational avoidance across different levels of academic writers? Situational avoidance reinforces fear. The person uses different situations to avoid doing the activity that he/she does not like. In this current study, the two situations identified are (a) when the learners felt that their personal reasons hinder them from writing. The next reason is (b) when the learners blame the instructor for making feel inadequate to write. 
(a) Learners' Reasons - Personal

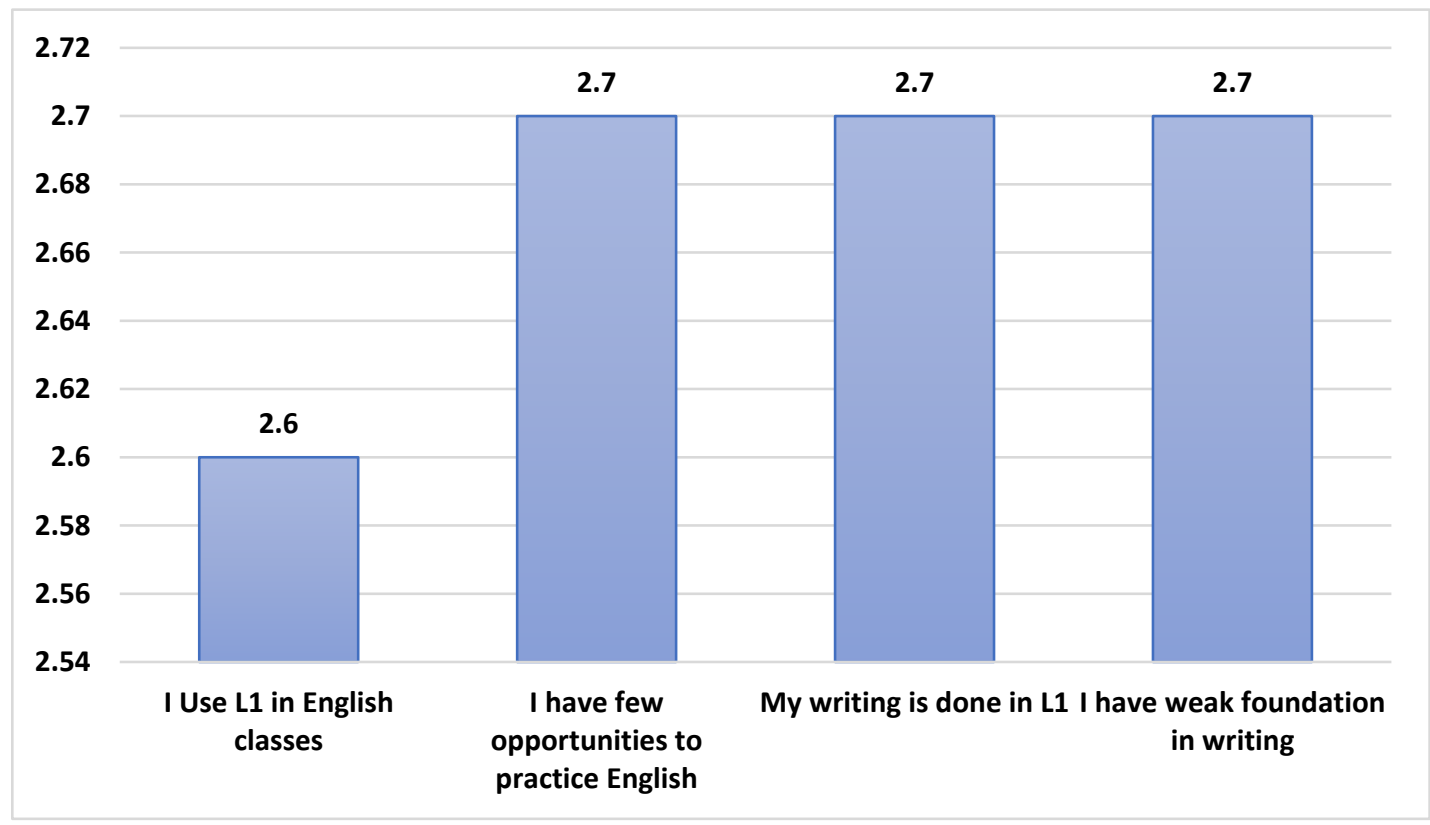

Figure 6a. Situational Avoidance: Learners' Reasons- Personal

Findings (figure 6a) reveal low mean scores for all items. Respondents reported that they "use L1 in English classes" (2.6). This low score means they did not use their L1 (first language) in English classes. Next, findings also show that respondents had "few opportunities to practice English"(2.7. Learners also reported low mean score for "writing done in L1" (2.7) which means not done in L1.

(b) Learners' Reasons -Teachers

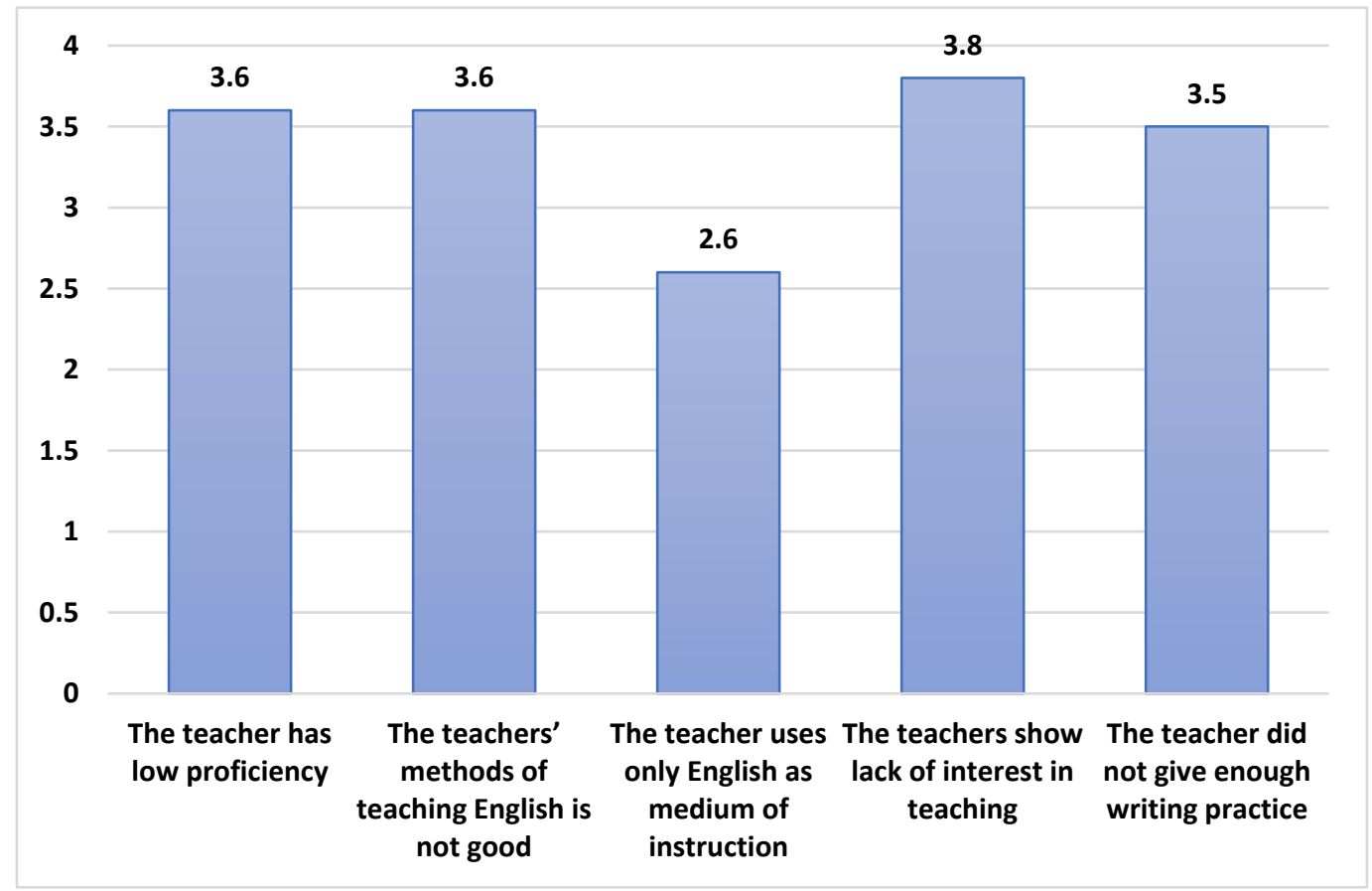

Figure 6b. Situational Avoidance: Learners' Reasons-Teachers 
With reference to figure $6 \mathrm{~b}$, the highest mean is for "teachers show lack of interest in teaching" (3.8), "teacher low proficiency" (3.6), and "teachers' method of teaching English not good (3.6).

\subsubsection{Protective Avoidance}

This section answers research question 4: What are the different facets of protective avoidance across different levels of academic writers? Sometimes, some writers protect themselves for writing by using their weakness as an excuse. This current study identified the protection avoidance as (a) problems with punctuation, (b) problems with language use, (c) problems with writing skills.

(c) Protective Avoidance: Problems with Punctuation

Figure $7 \mathrm{a}$ shows the mean score for protective avoidance -problems with punctuation. The highest mean is for the writers are "confused between colon and semi-colon" (4.1). They also have "problems with question marks, exclamation marks, commas "(4).

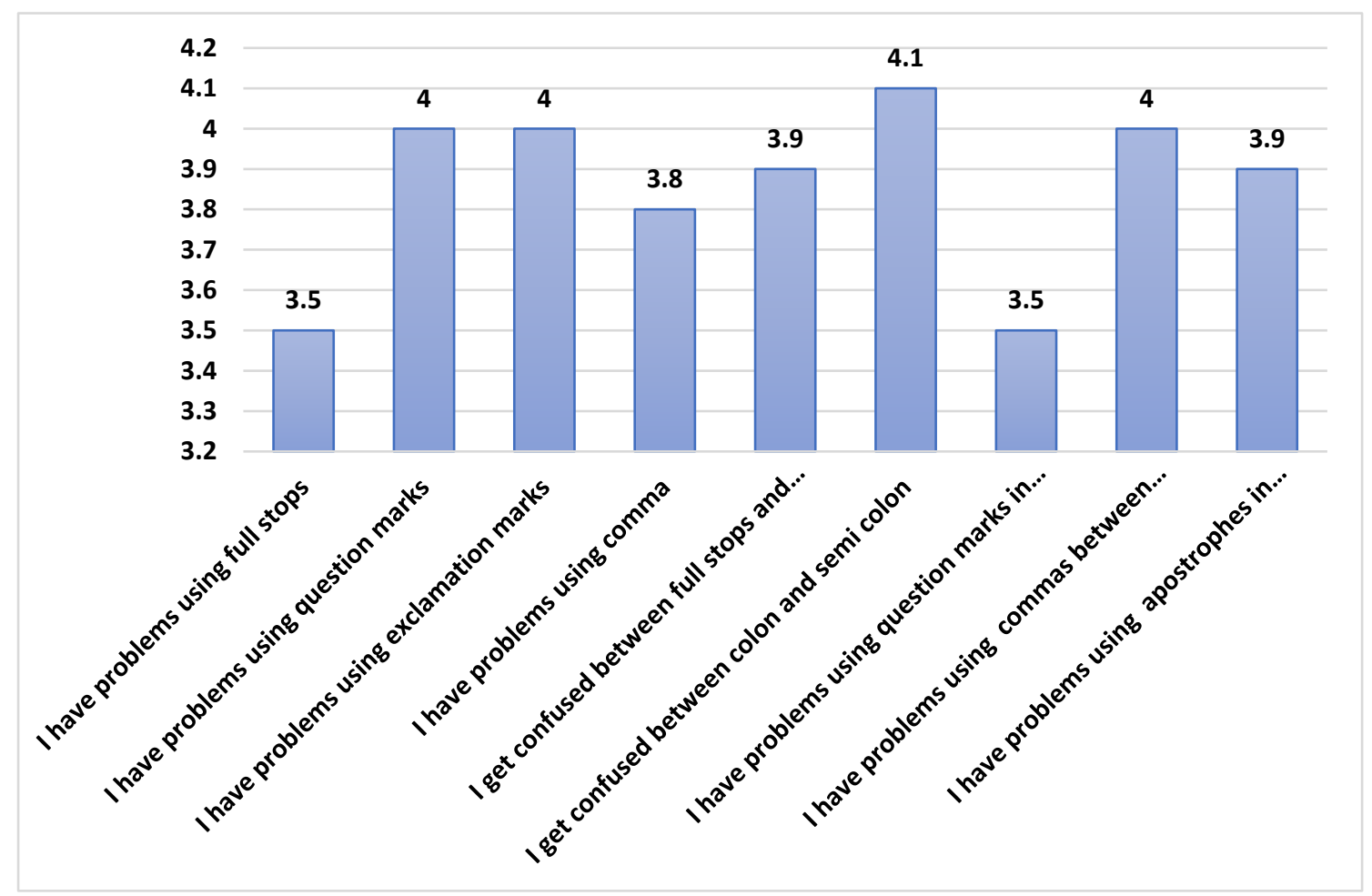

Figure 7a. Protective Avoidance (Problems with Punctuation)

(d) Protective Avoidance: Problems with Language Use

Figure $7 \mathrm{~b}$ displays the mean score for protective avoidance-problems with language use. The mean scores were low; respondents felt that they had problems with "tenses" (2.9). This is followed by "prepositions and articles (2.8). 


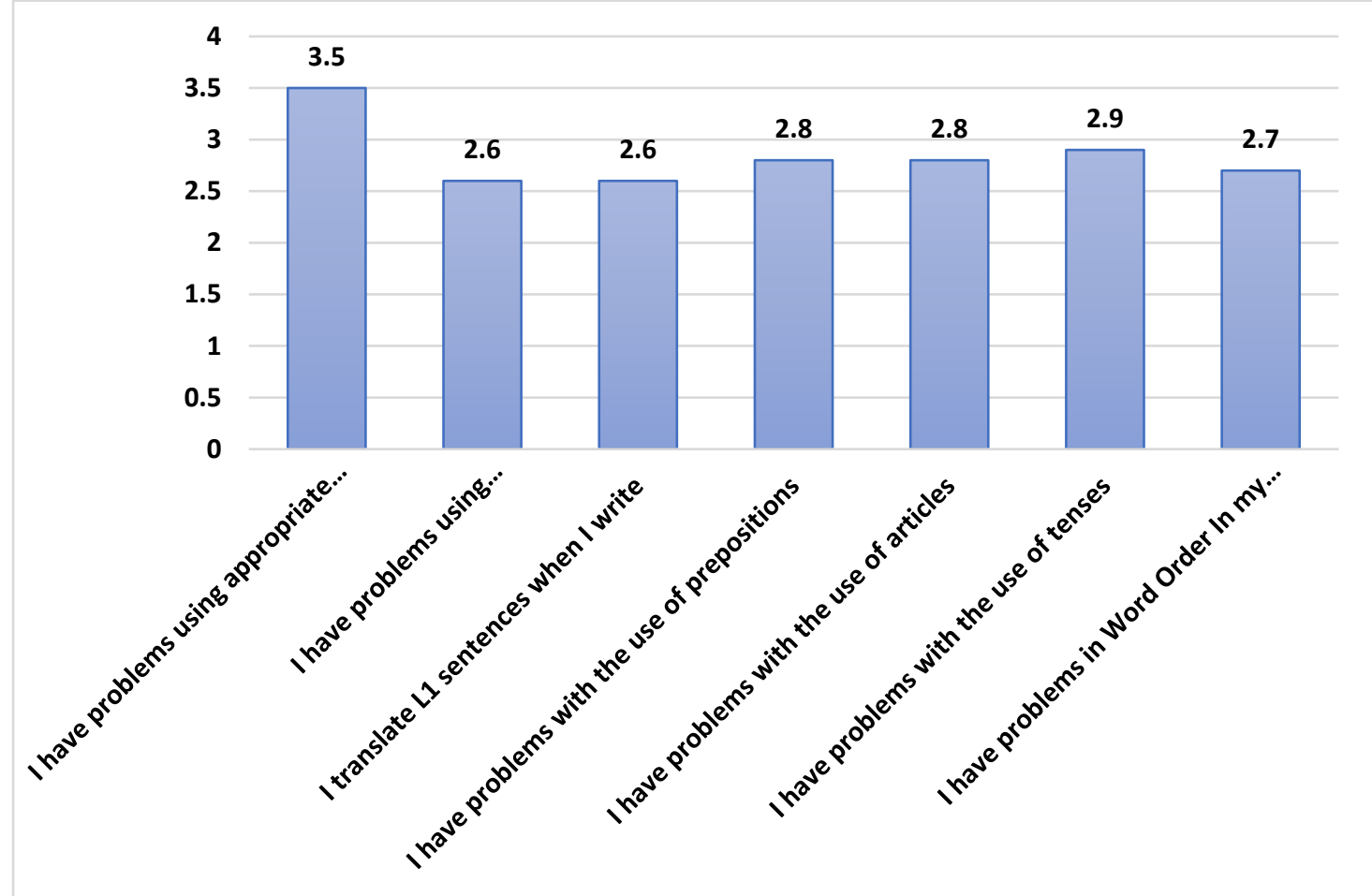

Figure 7b. Protective Avoidance: Problems with language Use

(e) Protective Avoidance: Problems with Writing Skills

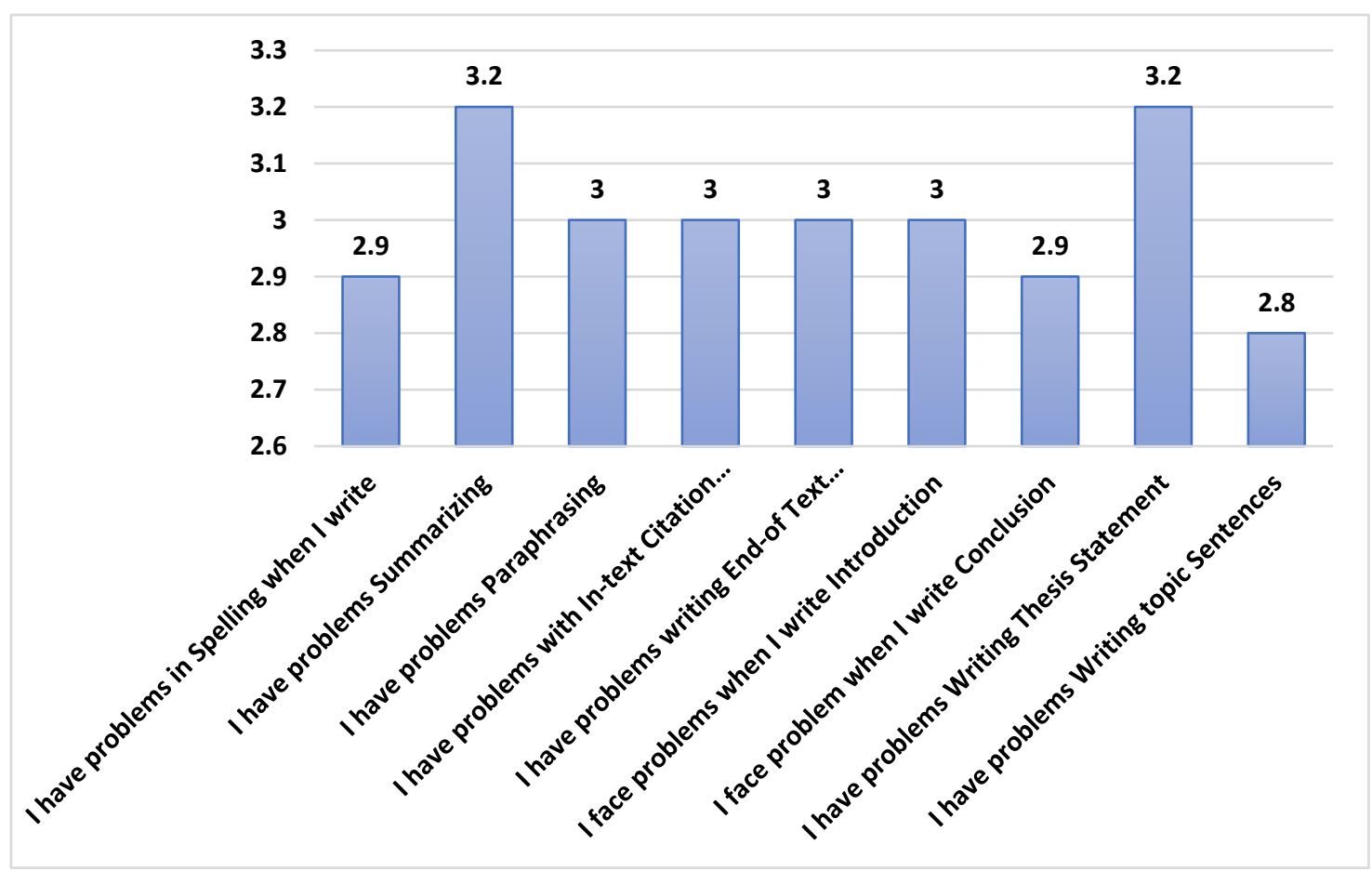

Figure 7c. Protective Avoidance (Problems with Writing Skills) 


\section{Macrothink}

The mean score for protective avoidance-problems with writing skills is presented in figure 7c. The highest mean score is "problems with "summarizing" (3.2) and problems with "thesis statement" (3.2).

\subsubsection{Substitution Avoidance}

This section answers research question 5: What are the different facets of protective avoidance across different levels of academic writers?

With reference to Figure 8, the highest mean is for "avoid situations in which I have to write in English" (3.1) , "unless I have no choice, I would not use English to write compositions" (3.1), "to my best to excuse myself if asked to write English compositions" (3.1) ","do my best to avoid writing English compositions" (3.0),

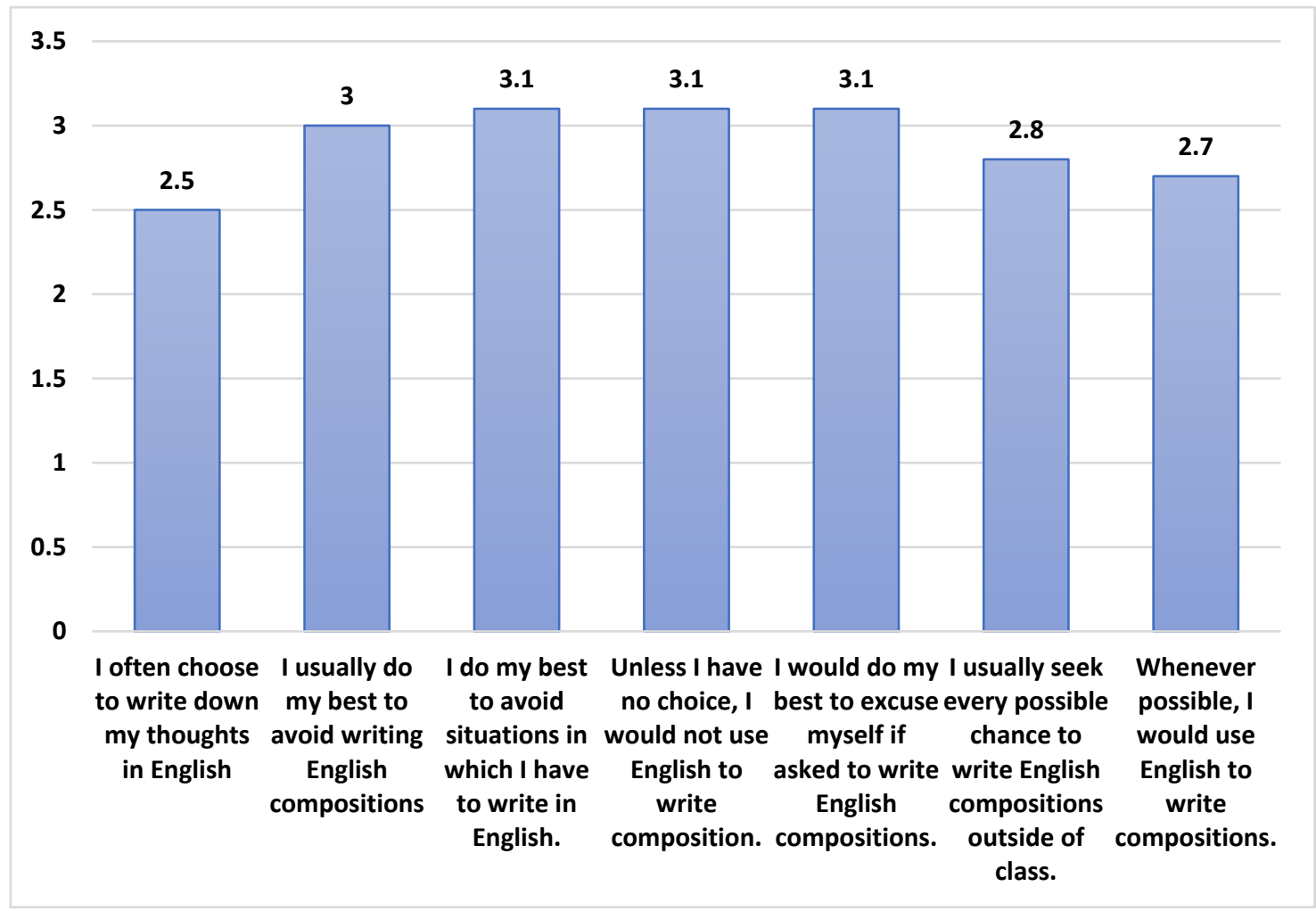

Figure 8. Substitution Behaviour

\section{Conclusion}

\subsection{Summary and Discussion}

Generally, learners use cognitive and somatic avoidance to steer their attention away from writing. They claim their fear of writing would hinder them from participating in writingrelated activities. Similarly, Ashraf and Bilal (2016) claimed that writing fear is a hindrance that many writers face either at the beginning of the writing process, during the writing process, 
or anytime throughout the writing experience.

Situational avoidance reinforces fear. Results of this current study showed that learners are affected by the situation around them. Learners used situational avoidance to steer them away from writing. This is also agreed by Fareed, Ashraf and Bilal (2016) who also reported situation factors like untrained teachers, ineffective teaching methods and examination system, lack of reading and writing practice, large classrooms, low motivation and lack of ideas as hindrance for learners to write.

Sometimes, some writers protect themselves for writing by using their weakness as an excuse. This current study identified the protection avoidance such as (a) problems with punctuation, (b) problems with language use, and (c) problems with writing skills.

Qasem and Zayed (2019) and Ibnian (2017)1 found similar findings and added that lack of vocabulary, grammar, and punctuation skills has become learners protective avoidance from writing.

\subsection{Pedagogical Implications}

From the situation perspective, writing should be taught by instructors who themselves not only can write but love to write. According to Fareed, Ashraf and Bilal (2016), the teaching of writing involves teaching of reading skills; conscious teaching vocab, develop writing culture, provide opportunities for writing practice. So, writing instructors need to have a passion for writing. The passion can then be transferred to the learners in the classroom setting. According to Kilmova (2014), writing instructors should put emphasis on the product as well as the process of writing.

In addition to that, Dudley-Evans \& St John (1998) introduce a third approach to writing - the social-constructionist approach, which takes account of individual writers and readers. It does not take into account the broader context of the writing process. Writing is seen as a social act in which writers have to be aware of the context in which they are writing. Perhaps writers should be taught to communicate with the audience. Writing is not merely a display of information for the readers to read. When writers can begin to want to write, then perhaps they would cease to display avoidance behaviour.

Future research could focus on investigating what makes some writers love writing and what aspects of writing attracts audience compared to other types.

\section{References}

Ariyanti, A., \& Fitriana, R. (2017). EFL Students' Difficulties and Needs in Essay Writing. Advances in Social Science, Education and Humanities Research (ASSEHR), 158, 111121.

Bradford, J. (2019). Why Writing Ability is the most important Skills in Business (and How to $\begin{array}{llll}\text { Acquire it) } \quad \text { Forbes. } & \text { Retrieved }\end{array}$ https://www.forbes.com/sites/forbesagencycouncil/2019/01/29/why-writing-ability-is- 
the-most-important-skill-in-business-and-how-to-acquire-it/\#7eca0cf42fdf

Brown, H. D. (2001). Teaching by Principles-An Interactive Approach to Language Pedagogy. NY: Longman

Cheng, Y. S. (2004). A measure of second language writing anxiety: Scale development and preliminary validation. Journal of Second Language Writing, 13(4), 313-335.

Dore, J. (2018). The Five Types of Avoidance. Psych Central Professional. Retrieved from https://pro.psychcentral.com/the-five-types-of-avoidance/

Dudley-Evans, T., \& St John, M. (1998). Developments in English for Specific Purposes. Cambridge: CUP.

Fadda, H. A. (2012). Difficulties in Academic Writing: from the Perspective of King Saud University Postgraduate Students. English Language Teaching, 593, 123-130.

Fareed, M., Ashraf, A., \& Bilal, M. (2016). ESL Learners' Writing Skills: Problems, Factors and Suggestions. Journal of Education \& Social Sciences, 492, 81-92.

Ibnian, S. S. K. (2017). Writing Difficulties Encountered by Jordanian EFL Learners. Asian Journal of Humanities and Social Studies, 5(3), 197-206.

Klimova, B. F. (2014). Constraints and Difficulties in the Process of Writing Acquisition. Procedia Social and Behvioural Science 122(2014). $2^{\text {nd }}$ World Conference on Design, Arts and Eductaion DAE-2013, 433-437.

Last, S., \& Neveu, C. (2019). Understanding the Rhetorical Situation. Technical Writing Essentials. Retrieved from https://pressbooks.bccampus.ca/technicalwriting/chapter/understandingrhetoricalsituatio $\mathrm{n} /$

Mohamed Alfaki, I. (2015). University Students' English Writing Problems: Diagnosis and Remedy. International Journal of English Language Teaching, 3(3), 40-52.

Moses, R. N., \& Mohamad, M. (2019). Challenges Faced by Students and Teachers on Writing Skills in ESL Contexts: A Literature Review. Creative Education, 10(13), 3385-3391.

Qasem, F., \& M.Zayid, E. I. (2019). The Challenges and Problems faced by Students in the early Stage of Writing Research Projects in L2, University of Bisha, Saudi Arabia. European Journal of Special Education Research, 4(1), 32-46. Retrieved from https://oapub.org/edu/index.php/ejse/article/view/2271

Rachman, S. (1977). The Conditioning of Fear-Acquisition: A Critical Examination. Bahvaioural Research Theory, 15, 375-387.

Rahmat, N. H. (2020). AN Investigation of Writers' Block through Rhetorical Situation. European Journal of English Language Teaching, 5(1), 1-14.

Rahmat, N. H. (2019a). Problems with Rhetorical Problems among Academic Writers. American Journal of Social Sciences and Humanities, 4(4), 506-515. 


\section{Macrothink}

Rahmat, N. H. (2019b). Cycle of Fear in learning: The Case for Three Language Skills. American Journal of Social Sciences and Humanities, 4(1), 151- 162.

Sabti, A. A., Md Rashid, S., Nimehchisalem, V., \& Darmi, R. (2019). The Impact of Writing Anxiety, Writing Achievement Motivation, and Writing Self-Efficacy on Writing performance: A Correlational Study of Iraqi Tertiary EFL Learners. SAGE Open. October-December 2019, 1-13. Retrieved from https://journals.sagepub.com/doi/pdf/10.1177/2158244019894289

Santrock, J. W. (2009). Educational Psychology (4th ed.) NY: McGraw-Hill Companies, Inc.

\section{Copyright Disclaimer}

Copyright for this article is retained by the author(s), with first publication rights granted to the journal.

This is an open-access article distributed under the terms and conditions of the Creative Commons Attribution license (http://creativecommons.org/licenses/by/3.0/). 